\title{
Recent Advances in the Cellular and Molecular Mechanisms of Hypothalamic Neuronal Glucose Detection
}

\author{
Xavier Fioramonti ${ }^{1,2 *}$, Chloé Chrétien ${ }^{2}$, Corinne Leloup ${ }^{2}$ and Luc Pénicaud ${ }^{2,3}$ \\ ${ }^{1}$ NutriNeuro, Institut National de la Recherche Agronomique, Université de Bordeaux, Bordeaux, France, ${ }^{2}$ Centre des \\ Sciences du Goût et de l'Alimentation, Centre National de la Recherche Scientifique, Institut National de la Recherche \\ Agronomique, Université Bourgogne Franche-Comté, Dijon, France, ${ }^{3}$ Stromalab, Centre National de la Recherche \\ Scientifique, Institut National de la Santé et de la Recherche Médicale, Université de Toulouse, Toulouse, France
}

The hypothalamus have been recognized for decades as one of the major brain centers for the control of energy homeostasis. This area contains specialized neurons able to detect changes in nutrients level. Among them, glucose-sensing neurons use glucose as a signaling molecule in addition to its fueling role. In this review we will describe the different sub-populations of glucose-sensing neurons present in the hypothalamus and highlight their nature in terms of neurotransmitter/neuropeptide expression. This review will particularly discuss whether pro-opiomelanocortin (POMC) neurons from the arcuate nucleus are directly glucose-sensing. In addition, recent observations in glucose-sensing suggest a subtle system with different mechanisms involved in the detection of changes in glucose level and their involvement in specific physiological functions. Several data point out the critical role of reactive oxygen species (ROS) and mitochondria dynamics in the detection of increased glucose. This review will also highlight that ATP-dependent potassium (K $\mathrm{K}_{\text {ATP }}$ ) channels are not the only channels mediating glucose-sensing and discuss the new role of transient receptor potential canonical channels (TRPC). We will discuss the recent advances in the determination of glucose-sensing machinery and propose potential line of research needed to further understand the regulation of brain glucose detection.

Keywords: glucose, hypothalamus, pro-opiomelanocortin neurons, transient receptor potential channels, reactive oxygen species, electrophysiology

Glucose homeostasis needs to be highly regulated to maintain blood glucose level constant. This is mandatory avoid any drop in blood glucose level as this nutrient is the preferred fuel source for the brain. Furthermore, increased blood glucose level also needs to be controlled to prevent long-term complication of excessive energy supply. Detection of changes in glucose level is achieved by glucose-sensors which work in concert to maintain glucose homeostasis. They are located at several anatomical sites at the periphery including taste buds of the tongue, the carotid bodies, the intestine, the portal vein, and the endocrine pancreas. In the central nervous system these sensors, called glucose-sensing neurons, are also localized in different brain areas. These neurons have initially been characterized in the hypothalamus. Even if they seem enriched within different hypothalamic nuclei, they have also been found in other areas including the brainstem, the cortex, 
the hippocampus, the thalamus, the amygdala, or the olfactory bulbs (see for review Steinbusch et al., 2015. Thus, glucosesensing neurons have been suggested to be involved (1) in the control of feeding initiation and termination and (2) through the modulation of the autonomic nervous system, in functions modulated in response to changes in brain glucose levels among which pancreatic hormonal secretion, $\beta$-cell proliferation, thermogenesis, and hepatic glucose production. The presence of these neurons in extra-hypothalamic or brainstem structures suggests that they could be involved in other physiological functions than the control of energy homeostasis such as memory, olfaction, motivation, or reward for instance. However, characterization of physiological functions modulated by glucose-sensing needs further attention. In this review, we will discuss the recent advances made on the role of hypothalamic glucose-sensing neurons in the control of energy homeostasis.

\section{CHARACTERIZATION OF HYPOTHALAMIC GLUCOSE-SENSING NEURONS}

The idea that specialized cells could detect changes in glucose level originated from Oomura' and Anand's groups (Anand et al., 1964; Oomura et al., 1964). Later, Oomura and colleagues conclusively demonstrated the presence of specialized glucosesensing neurons in showing that the direct electro-osmotic application of glucose altered the activity of hypothalamic neurons (Oomura et al., 1974). These neurons are now defined as cells able to adapt their electrical activity by directly detecting changes in extracellular glucose level. By definition, glucose-excited (GE) neurons increase their electrical activity when glucose level rises. By opposition, glucose-inhibited (GI) neurons increase their activity when glucose level decreases. It is important to note that glucose-sensing neurons directly detect changes in glucose level. In the brain, many neurons can see their electrical activity modulated by glucose but essentially due to presynaptic inputs coming from "true glucose-sensing" cells. Thus, in this review, we will refer as glucose-sensing cells, neurons which directly detect changes in glucose level.

Within the medio-basal hypothalamus, which contains both the arcuate (ARC) and ventromedian nuclei (VMN), four populations of glucose-sensing neurons have been characterized according to the changes in glucose level they detect. Evidence suggest that specialized glucose-sensing neurons detect changes in glucose level either above or below $2.5 \mathrm{mM}$ (Fioramonti et al., 2004; Wang et al., 2004; Penicaud et al., 2006; Chretien et al., 2017; Figure 1A). These neurons are referred as GE or

Abbreviations: $\alpha$-MSH, $\alpha$-melanocyte-stimulating hormone; ARC, arcuate nucleus; BBB, blood-brain-barrier; DMN, dorsomedian nucleus; GE neurons, glucose-excited neurons; GI neurons, glucose-inhibited neurons; GHRH, growth hormone-releasing hormone; GLUT, glucose transporter; GnRH, gonadotrophin releasing hormone; HGE neurons, high-glucose excited neurons; HGI neurons, high-glucose inhibited neurons; LH, lateral hypothalamus; KATP channel, potassium ATP-dependent channelMBH, mediobasal hypothalamus; $\mathrm{MCH}$, melanin-concentrating hormone; NPY, neuropeptide Y; PO, preoptic area; POMC, pro-opiomelanocortin; PVN, paraventricular nucleus; ROS, reactive oxygen species; SF1, steroidogenic factor 1; SGLT, sodium-glucose cotransporters; TRPC, transient receptor potential canonical; VMN, ventromedial nucleus.
GI neurons (respectively inhibited or activated in response to decreased glucose level below $2.5 \mathrm{mM}$ ) and HGE or HGI neurons (for high-glucose-excited or -inhibited, respectively activated or inhibited by changes above $2.5 \mathrm{mM}$ ). Interestingly, the electrical activity of GE and GI neurons is only changed in response to glucose change below $2.5 \mathrm{mM}$ and not altered by changes in glucose level above $2.5 \mathrm{mM}$ (Fioramonti et al., 2004; Wang et al., 2004). Similarly, we found that HGE and HGI neurons only change their electrical activity in response to changes in glucose level above $2.5 \mathrm{mM}$ but not below this level (Fioramonti et al., 2004). Finding these different sub-populations of glucose-sensing neurons enriched the debate on the glucose level present in the hypothalamus.

\section{Brain Glucose Levels}

The level of brain glucose is a process finely regulated. Glucose transporter 1 (GLUT1) seems to be the primary transporter controlling brain glucose entry (Cardoso et al., 2010). The high affinity of this transporter for glucose justifies the level found in the brain which is about $30 \%$ of the blood level and close to $2 \mathrm{mM}$ at baseline ( $\sim-8 \mathrm{mM}$ blood glucose). This is the case in the hypothalamus or other areas including the hippocampus and striatum for instance (McNay and Gold, 1999; McNay et al., 2001; de Vries et al., 2003; Dunn-Meynell et al., 2009; Langlet et al., 2013). Interestingly, hypothalamic glucose level does not seem to fluctuate significantly between meals (Dunn-Meynell et al., 2009) or even after fasting (Langlet et al., 2013). Langlet and colleagues even found that glucose level in the ARC is slightly increased after fasting due to an increased permeability of the blood-brain-barrier (BBB). Thus, only profound manipulations of blood glucose level would induce changes in hypothalamic levels including insulin-induced hypoglycemia or pathological hyperglycemia. Such conditions would make hypothalamic levels to fluctuate between 0.2 and $4.5 \mathrm{mM}$ (see for review Routh et al., 2014). Nevertheless, the finding of specialized neurons able to detect changes above 2.5 or even $5 \mathrm{mM}$ suggests that, in confined areas, glucose level could be increased closer to level found in the blood. This could be the case around fenestrated capillaries of the BBB present in the ventral part of the ARC (Ciofi, 2011; Langlet et al., 2013). In support of this hypothesis, HGE and HGI neurons have only been found in the ARC (Fioramonti et al., 2004) and not in the VMN (Song et al., 2001). In this later study, neurons activated by increased glucose level above $5 \mathrm{mM}$ have been found in the VMN but due to pre-synaptic glutamate inputs and not though a direct detection (Song et al., 2001). Local changes of glucose level around fenestrated capillaries would not be detectable by the available techniques including the microdialysis which does not present sufficient spatial resolution to monitor changes in confined environments. Determining (1) whether HGE- and HGI-like neurons can be found in extra-hypothalamic circumventricular organs in which the BBB is fenestrated (e.g., area postrema of the hindbrain, the subfornical organ and the vascular organ of lamina terminalis); (2) the real concentration of glucose in these micro-environments, will help characterizing brain spots containing these specialized glucose-sensing neurons as well as their physiological functions. 
A

\begin{tabular}{lcc}
$\substack{\text { Glucose level } \\
(\mathrm{mM})}$ & 0.5 & \\
\hline $\mathbf{G E}$ & inhibited & $\mathrm{X}$ \\
\hline $\mathbf{G I}$ & excited & $\mathrm{X}$ \\
\hline $\mathbf{H G E}$ & $\mathrm{X}$ & excited \\
\hline $\mathbf{H G I}$ & $\mathrm{X}$ & inhibited \\
\hline
\end{tabular}

B

\begin{tabular}{|c|c|c|c|c|c|c|c|c|c|c|c|c|}
\hline PO & \multicolumn{4}{|c|}{ ARC } & \multicolumn{2}{|c|}{ VMN } & \multicolumn{2}{|c|}{ DMN } & \multicolumn{2}{|c|}{ LH } & \multicolumn{2}{|l|}{ PVN } \\
\hline GE & GE & GI & HGE & HGI & GE & GI & GE & GI & GE & GI & GE & GI \\
\hline $\mathrm{GnRH}$ & POMC? & $\begin{array}{c}\text { NPY } \\
\text { GHRH }\end{array}$ & POMC? & GHRH & $\begin{array}{c}\text { SF1 } \\
?\end{array}$ & $\begin{array}{c}\text { SF1 } \\
?\end{array}$ & GABA & GABA & $\mathrm{MCH}$ & $\begin{array}{c}\text { orexin } \\
\text { NPY } \\
\text { GABA }\end{array}$ & Nesfatin-1 & $?$ \\
\hline
\end{tabular}

FIGURE 1 | Schematic overview of the changes in glucose level detected (A) and nature (B) of the four subtypes glucose-sensing neurons present in the hypothalamus. (A) GE and Gl neurons are respectively inhibited and activated by changes in glucose level below $2.5 \mathrm{mM}$ and are non-sensitive to change above $2.5 \mathrm{mM}$. By opposition, HGE and HGl neurons are respectively activated and inhibited by changes above 2.5 or $5 \mathrm{mM}$ while their activity is not altered by changes below $2.5 \mathrm{mM}$. The symbol "X" means that the electrical activity is not changed in comparison to the basal activity at $2.5 \mathrm{mM}$. (B) Nature of hypothalamic glucose-sensing neurons. ARC, arcuate nucleus; DMN, dorsomedian nucleus; LH, lateral hypothalamus; PVN, paraventricular nucleus; PO, pre-optic area; VMN, ventromedian nucleus. The symbol "?" means that the nature of glucose-sensing neurons has yet to be determined.

\section{NATURE OF HYPOTHALAMIC GLUCOSE-SENSING NEURONS}

In order to better appreciate the physiological role of glucosesensing neurons in the hypothalamus, several groups have dedicated means to determine the nature of these cells. Thus, studies have essentially tried to determine glucose-sensing properties of known neuropeptide-expressing neurons of the hypothalamus (Figure 1B). In the lateral hypothalamus (LH), orexin-, neuropeptide Y (NPY)-, and GABA-expressing neurons present GI-like properties whereas melanin-concentratinghormone (MCH) neurons are GE-type (Williams et al., 2001; Burdakov et al., 2005; Gonzalez et al., 2008; Karnani and Burdakov, 2011; Marston et al., 2011; Sheng et al., 2014). In the paraventricular nucleus (PVN), some GE neurons have been shown to be nesfatin-1-expressing cells (Sedbazar et al., 2014). The identity of the remaining glucose-sensing neurons in this nucleus has yet to be determined. In the dorsomedian nucleus (DMN), some GABAergic neurons are GE or GI neurons (OtgonUul et al., 2016). In the VMN, GE or GI neurons have been shown to express the transcription factor Steroidogenic factor 1 (SF1; Toda et al., 2016). This would suggest that VMN glucose-sensing neurons are glutamatergic since most of SF1 neurons express this neurotransmitter (McClellan et al., 2006; Tong et al., 2007). This hypothesis is supported by the study of Tong et al. showing that the counter-regulation to hypoglycemia is impaired in mice lacking glutamate release in VMN SF1 neurons. Nevertheless, VMN GE or GI neurons could express other neurotransmitter or neuropeptide since glutamate is not the only transmitter expressed in this nucleus or even in SF1 neurons (McClellan et al., 2006). In the anterior part of the hypothalamus, GnRH (gonadotrophin releasing hormone) neurons of the preoptic area (PO) are GE (Roland and Moenter, 2011a,b; Beall et al., 2012). Interestingly, only GnRH neurons of this area seem to be glucosesensing (Roland and Moenter, 2011b). In the ARC, we and others show that the large majority of GI neurons express NPY (Muroya et al., 1999; Fioramonti et al., 2007; Murphy et al., 2009). Stanley et al. also showed that ARC growth-hormone-releasing hormone (GHRH)-expressing neurons present GI- or HGI-like properties as they detect changes in the $0.2-10$ or $4-10 \mathrm{mM}$ windows level (Stanley et al., 2013). The nature of GE and HGE neurons is to debate as several studies show different results regarding their identity being POMC-expressing cells or not.

\section{Are POMC Neurons Glucose-Sensing Cells?}

Some studies using electrophysiology on brain slices suggested that POMC neurons could be either GE or HGE-type neurons as their activity is modulated by changes in extracellular glucose level (Ibrahim et al., 2003; Claret et al., 2007; Parton et al., 2007). Other studies including one from our lab did not find POMC neurons directly glucose-sensing (Wang et al., 2004; Fioramonti et al., 2007). Nevertheless, a study from Parton et al. showed that $\alpha$-melanocyte-stimulating hormone ( $\alpha$-MSH) release on hypothalamic chunks is increased in response to increased glucose level (Parton et al., 2007). This shows that POMC neurons can be activated by increased glucose level. Nevertheless, to our knowledge, no study has shown that glucose directly modulates the activity of POMC neurons. One could hypothesize that the modulation of POMC activity by glucose is due to presynaptic inputs rather than a direct detection by 
POMC neurons themselves. The hypothesis that POMC neurons would not detect changes in glucose level directly is supported by a recent work showing that the frequency of excitatory postsynaptic currents onto POMC neurons is modulated by glucose (Hu et al., 2014). To get further insight into the direct glucose-sensing properties of POMC neurons, we studied their activity using calcium-imaging on freshly dissociated hypothalamic cells from POMC-GFP mice (for detailed method, see Chretien et al., 2017). In such preparation, dissociated cells are not in contact from each other (Figure 2). Thus, this strategy allows the study of direct glucose-sensing properties of hypothalamic neurons (Dunn-Meynell et al., 2002; Kohno et al., 2003; Kang et al., 2004; Vazirani et al., 2013; Chretien et al., 2017). As presented in Figure 2, we found that $\sim 8 \%$ hypothalamic neurons tested were identified as HGE neurons as they harbor a transient increase in $\left[\mathrm{Ca}^{2+}\right]_{\mathrm{i}}$ in response to a raise in glucose level from 2.5 to $10 \mathrm{mM}$. Nevertheless, none of the HGE neurons identified were GFP-expressing neurons $(n=11$; Figure 2). Altogether, these data plus those from the literature suggest that glucose-sensing neurons modulate the melanocortin system but that POMC neurons themselves do not directly detect changes in glucose level. Further studies are still needed to determine the identity of ARC GE and HGE neurons. Knowing better the identity of hypothalamic (and extrahypothalamic) glucose-sensing neurons is necessary to decipher the physiological functions controlled by these neurons.

\section{MOLECULAR MECHANISMS INVOLVED IN HYPOTHALAMIC GLUCOSE-SENSING NEURONS}

The determination of the signaling pathways involved in the detection of changes in glucose level has aroused the scientific community for decades. Detailed mechanisms involved in GE and GI neurons can be found in the review from Routh et al. in this special issue. We will concentrate here on ionic channels and signaling pathways taking part in hypothalamic detection of increased glucose level. We will not discuss the role of the couple GLUT2/Glucokinase in the detection of increased glucose since it has been suggested a while ago. Interestingly, the most recent studies have rather shown their putative role in the detection of decreased glucose level and in the regulation of the counterregulatory response to hypoglycemia (Dunn-Meynell et al., 2002; Marty et al., 2005; Kang et al., 2006).

\section{Which Ion Channel(s) Are Involved in Glucose Detection?}

To determine mechanisms of brain glucose-sensing, studies have initially tried to determine similarities and differences from the known gold-standard glucose-sensor, the pancreatic $\beta$-cell (Yang et al., 1999). Thus, Michael Ashford was the first to show that ATP-dependent potassium $\left(\mathrm{K}_{\mathrm{ATP}}\right)$ channels are involved in glucose-sensing of GE neurons (Ashford et al., 1990a,b). Nevertheless, it is not possible to determine whether GE and/or HGE-like neurons were studied as those pioneer studies used large glucose changes from 0 to $10 \mathrm{mM}$. Later, studies from
Vanessa Routh's laboratory demonstrated that $\mathrm{K}_{\mathrm{ATP}}$ channels are indeed involved in the detection of decreased glucose level by GE neurons (2.5-0.1 mM level window; Song et al., 2001; Wang et al., 2004). Nevertheless, they showed that the change in $\mathrm{K}_{\mathrm{ATP}}$ conductance plateau above $2.5 \mathrm{mM}$ (Wang et al., 2004), suggesting that $\mathrm{K}_{\mathrm{ATP}}$ channels could only mediate detection below this level, and consequently, only in GE neurons. In addition, Guy Rutter's group suggested that $\mathrm{K}_{\mathrm{ATP}}$ channels would not be involved in glucose detection above $2.5 \mathrm{mM}$ in a study showing that intracellular ATP level is not increased in hypothalamic neurons in response to increased glucose level from 3 to $15 \mathrm{mM}$ (Ainscow et al., 2002). We confirmed that $\mathrm{K}_{\mathrm{ATP}}$ channels are not involved in HGE neurons. Indeed, we found that these channels are essentially closed at $5 \mathrm{mM}$. We also showed that HGE neurons can be found in $\mathrm{K}_{\mathrm{ATP}}$-deficient mice (Fioramonti et al., 2004) whereas GE neurons cannot be detected in these mice (Miki et al., 2001). Yang et al previously suggested that $\mathrm{K}_{\mathrm{ATP}}$-independent mechanisms would be involved in 5$20 \mathrm{mM}$ glucose detection as the $\mathrm{K}_{\mathrm{ATP}}$-opener diazoxide failed to prevent increased glucose detection (Yang et al., 1999). Instead, we found that a non-selective cationic conductance was involved in the glucose response of HGE neurons (Fioramonti et al., 2004). More recently, we demonstrated that transient-receptorpotential canonical type 3 (TRPC3) channels are required for glucose detection by HGE neurons (Chretien et al., 2017). Involvement of non-selective cationic conductance has also been identified in the response to glucose of GnRH neurons even though the identity of the channel responsible for glucosesensing in these neurons is yet to be determined (Roland and Moenter, 2011b). TRPC channels are involved in the response to insulin and leptin of ARC kisspeptin and POMC neurons (Qiu et al., 2010, 2011, 2014, 2017). Together, these studies open new line of research for hypothalamic glucose- and, more generally, nutrient-sensing mechanisms (Chretien et al., 2017).

\section{Role of the Mitochondrial Reactive Oxygen Species (mROS) in Glucose Detection}

The mitochondrial respiratory chain represents one the main sources of ROS. Increasing reduced equivalents $\left(\mathrm{NADH}, \mathrm{H}^{+}\right.$and $\mathrm{FADH}_{2}$ ) as a result of glucose oxidation leads to increased electron transfer chain activity, generating an elevated but physiological superoxide anions production. Our group showed that cerebral injection of glucose in rodents leads to a short-lived mROS signaling, in the form of $\mathrm{H}_{2} \mathrm{O}_{2}$ (see for review Leloup et al., 2011). We and others also showed that this increase in mROS level is necessary for the of glucose-sensing neurons to increased glucose (Chretien et al., 2017) and the regulation of food intake and insulin secretion (Leloup et al., 2006; Andrews et al., 2008; Colombani et al., 2009; Carneiro et al., 2012). Thus, increased mROS levels, rather than just the ATP/ADP ratio, constitute a signal that mediates the stimulatory effect of glucose on some hypothalamic neurons. Therefore, mROS signaling is consistent with the NADH mechanism suggested earlier for the glucose sensing mechanism (Yang et al., 1999; Ainscow and Rutter, 2002). In addition, the fact that TRPC 3 channels form a redox-sensitive 


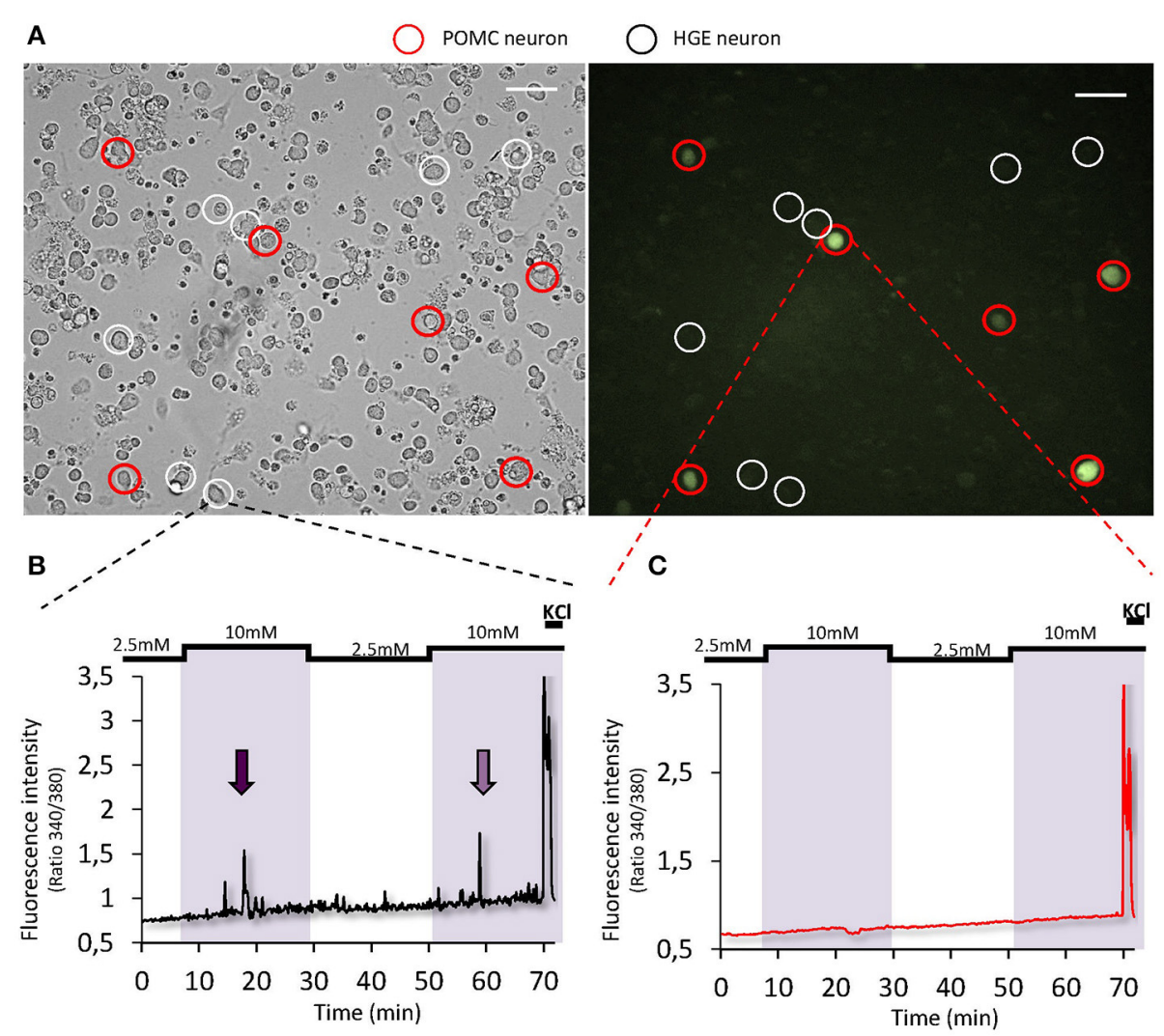

FIGURE 2 | Glucose-sensing properties of POMC neurons. (A) Representative bright-field (left panel) or fluorescence (right panel) images of cultured dissociated MBH neurons from POMC-GFP mice ( $\times 20$ objective, scale bar $=40 \mu \mathrm{m}$; Fioramonti et al., 2007). Detailed methods for cell culture preparation and calcium imaging recording is explained in Chretien et al. (2017). (B,C) Representative calcium imaging traces of a $\mathrm{HGE}$ (B) or a non-glucose-sensing POMC neuron (C) in response to 2 consecutives increased glucose level from 2.5 to $10 \mathrm{mM}$.

complex reinforces the role of mROS in the signaling involved in glucose detection.

Mitochondria are organized into a tubular network that continuously changes its shape and motility, mediated by fission and fusion mechanisms. Mitochondrial dynamics (fusion and fission) have been linked to the balance between energy demand and nutrient supply. Our group suggested that mitochondria dynamics (fission) play a significant role in mROS production in response to increased glucose level. In the $\mathrm{MBH}$, we highlighted glucose-induced Drp1-dependent mitochondrial fission is an upstream regulator for $\mathrm{mROS}$ signaling, and consequently, a key mechanism in hypothalamic glucose sensing (Carneiro et al., 2012). More recently, Diano's and Claret's teams showed that fission and fusion mechanisms are involved in the detection of increased or decreased glucose level by hypothalamic POMC or SF1 neurons (Schneeberger et al., 2013; Toda et al., 2016; Ramirez et al., 2017; Santoro et al., 2017). Even though the involvement of mitochondria dynamics seems to be a critical mechanism involved in glucose detection and in the regulation of energy and glucose homeostasis, the signaling pathways leading to such changes in mitochondria morphology is unclear and needs to be studied further. The idea that such mechanisms are specific to glucose-sensing neurons also needs to be addressed.

\section{What about Metabolism-Independent Glucose-Sensing Mechanisms?}

Some studies highlighted that metabolism-independent mechanisms take part in neuronal glucose-sensing. Thus, it has been shown that the sodium-glucose cotransporters (SGLT)inhibitor phloridzin, blocks the response to increased glucose level of some hypothalamic neurons (Yang et al., 1999; O’Malley et al., 2006). Furthermore, the non-metabolizable substrate of SGLTs, $\alpha$-methylglucopyranoside, mimics the effect of increased glucose level on a majority of HGE-like neurons (O'Malley et al., 2006). SGLT1 or SGLT3 could be the transporters responsible for glucose detection as they are expressed in hypothalamic neurons. The hypothesis on SGLT3 is particularly interesting since this transporter is expressed in human cholinergic neurons where it acts as a glucose-activated sodium channel which does not transport glucose (Diez-Sampedro et al., 2003). Interestingly, SGLT3 has been shown to be the sensor mediating glucose detection of the portal vein (Delaere et al., 2012).

Another metabolism-independent mechanism has been suggested to mediate glucose detection in the hypothalamus through sweet taste receptors. These receptors present in papillae of the tongue mediate the sweet sensation of sugars 
and sugar substitute (Laffitte et al., 2014). These receptors are heterodimers composed of T1R2/T1R3 subunits which have also been identified in several extra-gustatory tissues and cells including the pancreatic $\beta$-cell and the brain (Laffitte et al., 2014). In the brain, the expression of T1R2 and T1R3 subunits is particularly enriched in the ARC (Ren et al., 2009; Herrera-Moro Chao et al., 2016). Recently, Yada's group showed that half of the HGE-like neurons in the ARC (activated by the increase in glucose level from 1 to $10 \mathrm{mM}$ ) are excited by the application of the sweetener sucralose. They also showed that the sweet taste receptor inhibitor gurmarin, blocks the response to glucose of $2 / 3$ of HGE-like neurons (Kohno et al., 2016). Finally, in this study, they also show that sucralose activates neurons of the ARC which are not POMC neurons, reinforcing the idea that POMC neurons do not detect directly changes in glucose level. These data highlight a new mechanism involved in hypothalamic glucose-sensing. Further studies are however necessary to determine the physiological role of the sweet taste receptors expressed in hypothalamic glucose-sensing neurons in the control of energy homeostasis. It will also be interesting to determine the ionic channel mediating the effect of sweeteners or glucose downstream sweet taste receptor. The involvement of $\mathrm{K}_{\mathrm{ATP}}$ or TRPC channels has always been linked to metabolicdependent mechanisms. However, one could hypothesize that these channels mediate sweet taste receptor-dependent glucosesensing. Twik-related acid-sensitive potassium-like (TASK) 1/3 channels could also be a relevant candidate as they take part in metabolism-independent mechanism of orexin GI neurons in the LH (Gonzalez et al., 2008, 2009).

\section{CONCLUSION}

We described briefly the recent advances made in the comprehension of mechanisms involved in brain detection of increased glucose level. We highlighted the role of TRPC

\section{REFERENCES}

Ainscow, E. K., Mirshamsi, S., Tang, T., Ashford, M. L., and Rutter, G. A. (2002). Dynamic imaging of free cytosolic ATP concentration during fuel sensing by rat hypothalamic neurones: evidence for ATP-independent control of ATP-sensitive $\mathrm{K}(+)$ channels.[comment]. J. Physiol. 544, 2-45. doi: 10.1113/jphysiol.2002.022434

Ainscow, E. K., and Rutter, G. A. (2002). Glucose-stimulated oscillations in free cytosolic ATP concentration imaged in single islet beta-cells: evidence for a $\mathrm{Ca}^{2+}$-dependent mechanism. Diabetes 51(Suppl. 1), S162-S170. doi: 10.2337/diabetes.51.2007.S162

Anand, B. K., Chhina, G. S., Sharma, K. N., Dua, S., and Singh, B. (1964). Activity of single neurons in the hypothalamic feeding centers: effect of glucose. Am. J. Physiol. 207, 1146-1154.

Andrews, Z. B., Liu, Z. W., Walllingford, N., Erion, D. M., Borok, E., Friedman, J. M., et al. (2008). UCP2 mediates ghrelin's action on NPY/AgRP neurons by lowering free radicals. Nature 454, 846-851. doi: 10.1038/nature07181

Ashford, M. L., Boden, P. R., and Treherne, J. M. (1990a). Glucose-induced excitation of hypothalamic neurones is mediated by ATP- sensitive $\mathrm{K}+$ channels. Pflugers Arch. 415, 479-483.

Ashford, M. L. J., Boden, P. R., and Treherne, J. M. (1990b). Tolbutamide excites rat glucoreceptive ventromedial hypothalamic neurones by indirect inhibition of ATP-sensitive K+ channels. Br. J. Pharmacol. 101, 531-540. channels, ROS, mitochondria dynamics and pointed out that POMC neurons might not be directly sensing glucose. Nevertheless, additional studies are still needed to determine parts of the puzzle linking the pathways and whether they are activated in a same glucose-sensing neuron or whether several mechanisms are recruited in distinct neurons. We also highlighted that new lines of research are still needed to further characterize the nature of glucose-sensing neurons and to determine potential new locations within the brain. These data will help better understanding of the various physiological functions they control.

\section{ETHICS STATEMENT}

All procedures were performed in agreement with European Directive 2010/63/UE and approved by the French Ministry of Research and the local ethics committee of the University of Burgundy (C2EA Grand Campus Dijon $\mathrm{N}^{\circ} 105$; agreement $\mathrm{N}^{\circ}$ 02404.02).

\section{AUTHOR CONTRIBUTIONS}

Research data, CC. Wrote the manuscript, XF, LP, CC, and CL. Review/Edited the manuscript, XF, CC, LP, CL.

\section{ACKNOWLEDGMENTS}

Authors are thankful to S. Grall and C. Fenech (CSGA, Dijon, France) for their technical help in the cell culture preparation and to A. Lefranc, L. Decocq, and A. Mathou (CSGA, Dijon, France) for animal care taking. This work was supported by grants from Marie Curie Foundation (CIG NeuROSenS PCIG09GA-2011-293738, XF), Société Francophone du Diabète (XF). CC was supported by a salary award from the Institut National de la Recherche Agronomique (INRA).

Beall, C., Hamilton, D. L., Gallagher, J., Logie, L., Wright, K., Soutar, M. P., et al. (2012). Mouse hypothalamic GT1-7 cells demonstrate AMPKdependent intrinsic glucose-sensing behaviour. Diabetologia 55, 2432-2444. doi: 10.1007/s00125-012-2617-y

Burdakov, D., Gerasimenko, O., and Verkhratsky, A. (2005). Physiological changes in glucose differentially modulate the excitability of hypothalamic melaninconcentrating hormone and orexin neurons in situ. J. Neurosci. 25, 2429-2433. doi: 10.1523/JNEUROSCI.4925-04.2005

Cardoso, F. L., Brites, D., and Brito, M. A. (2010). Looking at the blood-brain barrier: molecular anatomy and possible investigation approaches. Brain Res. Rev. 64, 328-363. doi: 10.1016/j.brainresrev.2010.05.003

Carneiro, L., Allard, C., Guissard, C., Fioramonti, X., Tourrel-Cuzin, C., Bailbe, D., et al. (2012). Importance of mitochondrial dynamin-related protein 1 in hypothalamic glucose sensitivity in rats. Antioxid. Redox Signal. 17, 433-444. doi: 10.1089/ars.2011.4254

Chretien, C., Fenech, C., Lienard, F., Grall, S., Chevalier, C., Chaudy, S., et al. (2017). Transient Receptor Potential Canonical 3 (TRPC3) channels are required for hypothalamic glucose detection and energy homeostasis. Diabetes 66, 314-324. doi: 10.2337/db16-1114

Ciofi, P. (2011). The arcuate nucleus as a circumventricular organ in the mouse. Neurosci. Lett. 487, 187-190. doi: 10.1016/j.neulet.2010.10.019

Claret, M., Smith, M. A., Batterham, R. L., Selman, C., Choudhury, A. I., Fryer, L. G., et al. (2007). AMPK is essential for energy homeostasis regulation and 
glucose sensing by POMC and AgRP neurons. J. Clin. Invest. 117, 2325-2336. doi: 10.1172/JCI31516

Colombani, A. L., Carneiro, L., Benani, A., Galinier, A., Jaillard, T., Duparc, T., et al. (2009). Enhanced hypothalamic glucose sensing in obesity: alteration of redox signaling. Diabetes 58, 2189-2197. doi: 10.2337/db09-0110

Delaere, F., Duchampt, A., Mounien, L., Seyer, P., Duraffourd, C., Zitoun, C., et al. (2012). The role of sodium-coupled glucose co-transporter 3 in the satiety effect of portal glucose sensing. Mol. Metab. 2, 47-53. doi: 10.1016/j.molmet.2012.11.003

de Vries, M. G., Arseneau, L. M., Lawson, M. E., and Beverly, J. L. (2003). Extracellular glucose in rat ventromedial hypothalamus during acute and recurrent hypoglycemia. Diabetes 52, 2767-2773. doi: 10.2337/diabetes.52.11.2767

Diez-Sampedro, A., Hirayama, B. A., Osswald, C., Gorboulev, V., Baumgarten, K., Volk, C., et al. (2003). A glucose sensor hiding in a family of transporters. Proc. Natl. Acad. Sci. U.S.A. 100, 11753-11758. doi: 10.1073/pnas.1733027100

Dunn-Meynell, A. A., Routh, V. H., Kang, L., Gaspers, L., and Levin, B. E. (2002). Glucokinase is the likely mediator of glucosensing in both glucose- excited and glucose-inhibited central neurons. Diabetes 51, 2056-2065. doi: 10.2337/diabetes.51.7.2056

Dunn-Meynell, A. A., Sanders, N. M., Compton, D., Becker, T. C., Eiki, J., Zhang, B. B., et al. (2009). Relationship among brain and blood glucose levels and spontaneous and glucoprivic feeding. J. Neurosci. 29, 7015-7022. doi: 10.1523/JNEUROSCI.0334-09.2009

Fioramonti, X., Contie, S., Song, Z., Routh, V. H., Lorsignol, A., and Penicaud, L. (2007). Characterization of glucosensing neuron subpopulations in the arcuate nucleus: integration in neuropeptide $\mathrm{Y}$ and pro-opio melanocortin networks? Diabetes 56, 1219-1227. doi: 10.2337/db06-0567

Fioramonti, X., Lorsignol, A., Taupignon, A., and Penicaud, L. (2004). A new ATP-sensitive $\mathrm{K}+$ channel-independent mechanism is involved in glucose-excited neurons of mouse arcuate nucleus. Diabetes 53, 2767-2775. doi: 10.2337/diabetes.53.11.2767

Gonzalez, J. A., Jensen, L. T., Fugger, L., and Burdakov, D. (2008). Metabolismindependent sugar sensing in central orexin neurons. Diabetes 57, 2569-2576. doi: $10.2337 / \mathrm{db} 08-0548$

Gonzalez, J. A., Reimann, F., and Burdakov, D. (2009). Dissociation between sensing and metabolism of glucose in sugar sensing neurones. J. Physiol. 587, 41-48. doi: 10.1113/jphysiol.2008.163410

Herrera-Moro Chao, D., Leon-Mercado, L., Foppen, E., Guzman-Ruiz, M., Basualdo, M. C., Escobar, C., et al. (2016). The suprachiasmatic nucleus modulates the sensitivity of arcuate nucleus to hypoglycemia in the male rat. Endocrinology 157, 3439-3451. doi: 10.1210/en.2015-1751

Hu, J., Jiang, L., Low, M. J., and Rui, L. (2014). Glucose rapidly induces different forms of excitatory synaptic plasticity in hypothalamic POMC neurons. PLoS ONE 9:e105080. doi: 10.1371/journal.pone.0105080

Ibrahim, N., Bosch, M. A., Smart, J. L., Qiu, J., Rubinstein, M., Ronnekleiv, O. K., et al. (2003). Hypothalamic proopiomelanocortin neurons are glucose responsive and express K(ATP) channels. Endocrinology 144, 1331-1340. doi: 10.1210/en.2002-221033

Kang, L., Dunn-Meynell, A. A., Routh, V. H., Gaspers, L. D., Nagata, Y., Nishimura, T., et al. (2006). Glucokinase is a critical regulator of ventromedial hypothalamic neuronal glucosensing. Diabetes 55, 412-420. doi: 10.2337/diabetes.55.02.06.db05-1229

Kang, L., Routh, V. H., Kuzhikandathil, E. V., Gaspers, L. D., and Levin, B. E. (2004). Physiological and molecular characteristics of rat hypothalamic ventromedial nucleus glucosensing neurons. Diabetes 53, 549-559. doi: 10.2337/diabetes.53.3.549

Karnani, M., and Burdakov, D. (2011). Multiple hypothalamic circuits sense and regulate glucose levels. Am. J. Physiol. Regul. Integr. Comp. Physiol. 300, R47-R55. doi: 10.1152/ajpregu.00527.2010

Kohno, D., Gao, H. Z., Muroya, S., Kikuyama, S., and Yada, T. (2003). Ghrelin directly interacts with neuropeptide-Y-containing neurons in the rat arcuate nucleus: $\mathrm{Ca} 2+$ signaling via protein kinase $\mathrm{A}$ and N-type channel-dependent mechanisms and cross-talk with leptin and orexin. Diabetes 52, 948-956. doi: 10.2337/diabetes. 52.4.948

Kohno, D., Koike, M., Ninomiya, Y., Kojima, I., Kitamura, T., and Yada, T. (2016). Sweet Taste receptor serves to activate glucose- and leptin-responsive neurons in the hypothalamic arcuate nucleus and participates in glucose responsiveness. Front. Neurosci. 10:502. doi: 10.3389/fnins.2016.00502

Laffitte, A., Neiers, F., and Briand, L. (2014). Functional roles of the sweet taste receptor in oral and extraoral tissues. Curr. Opin. Clin. Nutr. Metab. Care 17, 379-385. doi: 10.1097/MCO.0000000000000058

Langlet, F., Levin, B. E., Luquet, S., Mazzone, M., Messina, A., Dunn-Meynell, A. A., et al. (2013). Tanycytic VEGF-A boosts blood-hypothalamus barrier plasticity and access of metabolic signals to the arcuate nucleus in response to fasting. Cell Metab. 17, 607-617. doi: 10.1016/j.cmet.2013.03.004

Leloup, C., Casteilla, L., Carriere, A., Galinier, A., Benani, A., Carneiro, L., et al. (2011). Balancing mitochondrial redox signaling: a key point in metabolic regulation. Antioxid. Redox Signal. 14, 519-530. doi: 10.1089/ars.2010.3424

Leloup, C., Magnan, C., Benani, A., Bonnet, E., Alquier, T., Offer, G., et al. (2006). Mitochondrial reactive oxygen species are required for hypothalamic glucose sensing. Diabetes 55, 2084-2090. doi: 10.2337/db06-0086

Marston, O. J., Hurst, P., Evans, M. L., Burdakov, D. I., and Heisler, L. K. (2011). Neuropeptide Y cells represent a distinct glucose-sensing population in the lateral hypothalamus. Endocrinology 152, 4046-4052. doi: 10.1210/en.2011-1307

Marty, N., Dallaporta, M., Foretz, M., Emery, M., Tarussio, D., Bady, I., et al. (2005). Regulation of glucagon secretion by glucose transporter type 2 (glut2) and astrocyte-dependent glucose sensors. J. Clin. Invest. 115, 3545-3553. doi: 10.1172/JCI26309

McClellan, K. M., Parker, K. L., and Tobet, S. (2006). Development of the ventromedial nucleus of the hypothalamus. Front. Neuroendocrinol. 27, 193-209. doi: 10.1016/j.yfrne.2006.02.002

McNay, E. C., and Gold, P. E. (1999). Extracellular glucose concentrations in the rat hippocampus measured by zero-net-flux: effects of microdialysis flow rate, strain, and age. J. Neurochem. 72, 785-790. doi: 10.1046/j.1471-4159.1999.720785.x

McNay, E. C., McCarty, R. C., and Gold, P. E. (2001). Fluctuations in brain glucose concentration during behavioral testing: dissociations between brain areas and between brain and blood. Neurobiol. Learn. Mem. 75, 325-337. doi: 10.1006/nlme.2000.3976

Miki, T., Liss, B., Minami, K., Shiuchi, T., Saraya, A., Kashima, Y., et al. (2001). ATP-sensitive $\mathrm{K}+$ channels in the hypothalamus are essential for the maintenance of glucose homeostasis. Nat. Neurosci. 4, 507-512. doi: $10.1038 / 87455$

Muroya, S., Yada, T., Shioda, S., and Takigawa, M. (1999). Glucose-sensitive neurons in the rat arcuate nucleus contain neuropeptide Y. Neurosci. Lett. 264, 113-116. doi: 10.1016/S0304-3940(99)00185-8

Murphy, B. A., Fioramonti, X., Jochnowitz, N., Fakira, K., Gagen, K., Contie, S., et al. (2009). Fasting enhances the response of arcuate neuropeptide Y-glucoseinhibited neurons to decreased extracellular glucose. Am. J. Physiol. Cell Physiol. 296, C746-C756. doi: 10.1152/ajpcell.00641.2008

O'Malley, D., Reimann, F., Simpson, A. K., and Gribble, F. M. (2006). Sodiumcoupled glucose cotransporters contribute to hypothalamic glucose sensing. Diabetes 55, 3381-3386. doi: 10.2337/db06-0531

Oomura, Y., Kimura, K., Ooyama, H., Maeo, T., Iki, M., and Kuniyoshi, N. (1964). Reciprocal activities of the ventromedial and lateral hypothalamic area of cats. Science 143, 484-485. doi: 10.1126/science.143.3605.484

Oomura, Y., Ooyama, H., Sugimori, M., Nakamura, T., and Yamada, Y. (1974). Glucose inhibition of the glucose-sensitive neurone in the rat lateral hypothalamus. Nature 247, 284-286. doi: 10.1038/247284a0

Otgon-Uul, Z., Suyama, S., Onodera, H., and Yada, T. (2016). Optogenetic activation of leptin- and glucose-regulated GABAergic neurons in dorsomedial hypothalamus promotes food intake via inhibitory synaptic transmission to paraventricular nucleus of hypothalamus. Mol. Metab. 5, 709-715. doi: 10.1016/j.molmet.2016.06.010

Parton, L. E., Ye, C. P., Coppari, R., Enriori, P. J., Choi, B., Zhang, C. Y., et al. (2007). Glucose sensing by POMC neurons regulates glucose homeostasis and is impaired in obesity. Nature 449, 228-232. doi: 10.1038/nature06098

Penicaud, L., Leloup, C., Fioramonti, X., Lorsignol, A., and Benani, A. (2006). Brain glucose sensing: a subtle mechanism. Curr. Opin. Clin. Nutr. Metab. Care 9, 458-462. doi: 10.1097/01.mco.0000232908.84483.e0

Qiu, J., Fang, Y., Bosch, M. A., Ronnekleiv, O. K., and Kelly, M. J. (2011). Guinea pig kisspeptin neurons are depolarized by leptin via activation of TRPC channels. Endocrinology 152, 1503-1514. doi: 10.1210/en.2010-1285 
Qiu, J., Fang, Y., Ronnekleiv, O. K., and Kelly, M. J. (2010). Leptin excites proopiomelanocortin neurons via activation of TRPC channels. J. Neurosci. 30, 1560-1565. doi: 10.1523/JNEUROSCI.4816-09.2010

Qiu, J., Wagner, E. J., Ronnekleiv, O. K., and Kelly, M. J. (2017). Insulin and leptin excite anorexigenic proopiomelanocortin neurons via activation of TRPC5 channels. J. Neuroendocrinol. doi: 10.1111/jne.12501. [Epub ahead of print].

Qiu, J., Zhang, C., Borgquist, A., Nestor, C. C., Smith, A. W., Bosch, M. A., et al. (2014). Insulin excites anorexigenic proopiomelanocortin neurons via activation of canonical transient receptor potential channels. Cell Metab. 19, 682-693. doi: 10.1016/j.cmet.2014.03.004

Ramirez, S., Gomez-Valades, A. G., Schneeberger, M., Varela, L., Haddad-Tovolli, R., Altirriba, J., et al. (2017). Mitochondrial dynamics mediated by mitofusin 1 is required for POMC neuron glucose-sensing and insulin release control. Cell Metab. 25, 1390-1399.e6. doi: 10.1016/j.cmet.2017.05.010

Ren, X., Zhou, L., Terwilliger, R., Newton, S. S., and de Araujo, I. E. (2009). Sweet taste signaling functions as a hypothalamic glucose sensor. Front. Integr. Neurosci. 3:12. doi: 10.3389/neuro.07.012.2009

Roland, A. V., and Moenter, S. M. (2011a). Glucosensing by GnRH neurons: inhibition by androgens and involvement of AMP-activated protein kinase. Mol. Endocrinol. 25, 847-858. doi: 10.1210/me.2010-0508

Roland, A. V., and Moenter, S. M. (2011b). Regulation of gonadotropinreleasing hormone neurons by glucose. Trends Endocrinol. Metab. 22, 443-449. doi: 10.1016/j.tem.2011.07.001

Routh, V. H., Hao, L., Santiago, A. M., Sheng, Z., and Zhou, C. (2014). Hypothalamic glucose sensing: making ends meet. Front. Syst. Neurosci. 8:236. doi: $10.3389 /$ fnsys.2014.00236

Santoro, A., Campolo, M., Liu, C., Sesaki, H., Meli, R., Liu, Z. W., et al. (2017). DRP1 suppresses leptin and glucose sensing of POMC neurons. Cell Metab. 25, 647-660. doi: 10.1016/j.cmet.2017.01.003

Schneeberger, M., Dietrich, M. O., Sebastian, D., Imbernon, M., Castano, C., Garcia, A., et al. (2013). Mitofusin 2 in POMC neurons connects ER stress with leptin resistance and energy imbalance. Cell 155, 172-187. doi: 10.1016/j.cell.2013.09.003

Sedbazar, U., Ayush, E. A., Maejima, Y., and Yada, T. (2014). Neuropeptide Y and $\alpha$-melanocyte-stimulating hormone reciprocally regulate nesfatin-1 neurons in the paraventricular nucleus of the hypothalamus. Neuroreport 25, 1453-1458. doi: 10.1097/WNR.0000000000000293

Sheng, Z., Santiago, A. M., Thomas, M. P., and Routh, V. H. (2014). Metabolic regulation of lateral hypothalamic glucose-inhibited orexin neurons may influence midbrain reward neurocircuitry. Mol. Cell. Neurosci. 62, 30-41. doi: 10.1016/j.mcn.2014.08.001

Song, Z., Levin, B. E., McArdle, J. J., Bakhos, N., and Routh, V. H. (2001). Convergence of pre- and postsynaptic influences on glucosensing neurons in the ventromedial hypothalamic nucleus. Diabetes 50, 2673-2681. doi: 10.2337/diabetes.50.12.2673

Stanley, S., Domingos, A. I., Kelly, L., Garfield, A., Damanpour, S., Heisler, L., et al. (2013). Profiling of glucose-sensing neurons reveals that GHRH neurons are activated by hypoglycemia. Cell Metab. 18, 596-607. doi: 10.1016/j.cmet.2013.09.002

Steinbusch, L., Labouebe, G., and Thorens, B. (2015). Brain glucose sensing in homeostatic and hedonic regulation. Trends Endocrinol. Metab. 26, 455-466. doi: 10.1016/j.tem.2015.06.005

Toda, C., Kim, J. D., Impellizzeri, D., Cuzzocrea, S., Liu, Z. W., and Diano, S. (2016). UCP2 regulates mitochondrial fission and ventromedial nucleus control of glucose responsiveness. Cell 164, 872-883. doi: 10.1016/j.cell.2016.02.010

Tong, Q., Ye, C., McCrimmon, R. J., Dhillon, H., Choi, B., Kramer, M. D., et al. (2007). Synaptic glutamate release by ventromedial hypothalamic neurons is part of the neurocircuitry that prevents hypoglycemia. Cell Metab. 5, 383-393. doi: 10.1016/j.cmet.2007.04.001

Vazirani, R. P., Fioramonti, X., and Routh, V. H. (2013). Membrane potential dye imaging of ventromedial hypothalamus neurons from adult mice to study glucose sensing. J. Vis. Exp. e50861. doi: 10.3791/50861

Wang, R., Liu, X., Hentges, S. T., Dunn-Meynell, A. A., Levin, B. E., Wang, W., et al. (2004). The regulation of glucose-excited neurons in the hypothalamic arcuate nucleus by glucose and feeding-relevant peptides. Diabetes 53, 1959-1965. doi: 10.2337/diabetes.53.8.1959

Williams, G., Bing, C., Cai, X. J., Harrold, J. A., King, P. J., and Liu, X. H. (2001). The hypothalamus and the control of energy homeostasis: different circuits, different purposes. Physiol. Behav. 74, 683-701. doi: 10.1016/S0031-9384(01)00612-6

Yang, X. J., Kow, L. M., Funabashi, T., and Mobbs, C. V. (1999). Hypothalamic glucose sensor: similarities to and differences from pancreatic beta-cell mechanisms. Diabetes 48, 1763-1772. doi: 10.2337/diabetes.48.9.1763

Conflict of Interest Statement: The authors declare that the research was conducted in the absence of any commercial or financial relationships that could be construed as a potential conflict of interest.

The reviewer GTD and handling Editor declared their shared affiliation.

Copyright (c) 2017 Fioramonti, Chrétien, Leloup and Pénicaud. This is an open-access article distributed under the terms of the Creative Commons Attribution License (CC $B Y)$. The use, distribution or reproduction in other forums is permitted, provided the original author(s) or licensor are credited and that the original publication in this journal is cited, in accordance with accepted academic practice. No use, distribution or reproduction is permitted which does not comply with these terms. 